\title{
Venting grief for vocational erosion
}

\section{Abi Berger}

General Practitioner, London, UK

Correspondence to

Dr Abi Berger c/o

journal@fsrh.org

Received 17 August 2016 Accepted 23 August 2016

\section{CrossMark}

To cite: Berger A. J Fam Plann Reprod Health Care 2016;42:297.
I've been grieving. I've slowly realised that doctors' sense of vocation in the National Health Service (NHS), perhaps that of other professions too, seems to have become eroded. Having worked for years with a very stable cohort who have been growing old alongside me, I've been working more recently with general practitioners (GPs) who are fresh out of training. The new generation strikes me as harbingers of a culture I don't recognise and am not sure I want to. But it is after all how they are being trained to survive the NHS, and also perhaps to help the NHS to survive.

Apparently I am not alone in detecting a shift - hospital consultant friends, too, confirm my sense that being a competent doctor is no longer about being interested in people, relationships or continuity, but about adhering to protocols, getting your clinical record straight, and getting people out of the door as soon as possible. Discarding clinical examination in favour of a request for scans is now apparently common. Even the traditional "take a history, examine the patient, decide if any tests are necessary and come to a working hypothesis about what's wrong" approach appears to be giving way to variants such as "take a history on the phone, secondguess what might be going on, order some tests and then make an appointment". Whatever happened to the laying of hands on the patient?

There's a lot else that I find myself missing, too. I miss curiosity as to why a patient books an appointment to see a clinician - a skill abandoned, it seems, in favour of acquiring the skill of juggling the excruciatingly short 10-minute appointment, making sure nothing important is missed, and onto the next patient. Medicine has become a transactional game in which the doctor's (or the healthcare system's) agenda often seems to trump the patient's. As more and more GPs choose to work as locums, patients are missing out on the patient-doctor relationship. But so am I, the doctor. What about my newly trained doctors, so skilled in the 10-minute juggling act - don't they miss this too, even though they haven't known it?

Where they succeed, I frequently fail. My attempts to keep to time in 10-minute appointments have failed for a long time. As more has been required of us in each appointment, from patients, but also with the ever increasing mountain of contractual requirements, my refusal to jettison the doctor-patient relationship or my curiosity means my timekeeping has fallen further behind. I've introduced more 'catch-up slots' and found acceptable ways to apologise for keeping patients waiting, but I still can't keep to time. I have tried and failed to change my consultation style.

With patients I've known for years, it's usually fine. But with patients who just happen to find themselves booked into my sessions, it's another story. With a heavy heart, I'm also grieving the fact that there are patients who don't want the holistic, curious approach either. They just want the tests, the diagnosis, and the prescription. And sometimes they too just want all of that over the phone. And of course, that's my issue - not theirs.

A committed GP, with a following of loyal patients, I am at times left feeling a failure - as measured against standards which don't seem to fit my vocation. One weekend recently, after soldiering through a busy week, undone by a piece of Rachmaninov, the grief hit me with full force. I found myself sobbing, repeatedly, "I just want to be a doctor!". The grief is mine. But the vocational erosion affects us all.

Competing interests None declared.

Provenance and peer review Commissioned; internally peer reviewed. 